\title{
DE RE RUSTICA DE COLUMELA E GEÓRGICAS IV DE VIRGÍLIO: ESTUDO CRÍTICO-COMPARATIVO*
}

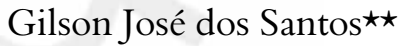 \\ Universidade Estadual de Campinas
}

\begin{abstract}
In the study we analyse comparatively selected fragments from Georgics IV and De re rustica (Book IX) in order to understand a little better the linguistic-literary treatment due to the distinct generic orientations the authors deliver to their works. The dominating compounding and stylistic characteristics in the texts are studied and are used as instruments to analyse (a) the constitutive particularities of the genders, didactic poetry and technical treatise (in prose), and (b) the aspects related to the construction of the particular meanings in the works. The theoretical reference marks for the text studies are: the literary genders theory, literary stylistic (referring to the Roman agrarian literature) and the history of Roman literature.
\end{abstract}

KEYWORDS: Roman agrarian literature; didactic poetry; technical treatise; Georgics; De re rustica.

\footnotetext{
* Este artigo resulta de nossa Dissertação de Mestrado na Faculdade de Letras da UFMG, como bolsista CAPES e sob orientação do Prof. Dr. Matheus Trevizam, a quem agradeço publicamente pela orientação cuidadosa e sugestões valiosas durante o desenvolvimento da pesquisa. Título da Dissertação: Literatura agrária latina: tradução e estudo do "De Re Rustica" (livro IX) de Columela, e "Geórgicas" (canto IV), de Virgílio.
}

$\star \star$ gilsonsantos2105@hotmail.com 


\section{Introdução}

De re rustica de Columela é considerado, por vezes, não somente o opus magnum do agrônomo romano, senão o mais importante tratado técnico que se conservou a respeito da atividade rural da Antiguidade (romana). ${ }^{1}$ Nessa obra, que abriga doze livros em prosa, exceto o livro $\mathrm{X}$ - De cultu hortorum, "Da cultura do horto" —, escrito em hexâmetro datílico e idealizado como um complemento às Geórgicas IV de Virgílio, o agrônomo oferece um conjunto de instruções e técnicas minuciosas aos leitores a respeito da atividade rural na Itália antiga. De modo geral, os traços distintivos desse gênero literário são (a) o emprego de língua técnica agrícola, ${ }^{2}$ que se distingue sobretudo pelo léxico especializado, ${ }^{3}$ (b) o estilo elevado, ${ }^{4}$ que a partir do medievo representaria um obstáculo à difusão dessa obra, ${ }^{5}$ (c) a busca constante da uariatio na sintaxe e no léxico, (d) o gosto pela disposição simétrica ou correlativa dos membros da frase, (e) a observância das normas da prosa métrica ${ }^{6} \mathrm{e}(\mathrm{f})$ a personificação e descrição recorrentes. ${ }^{7}$ A esses elementos estilístico-formais do gênero, une-se um modo didático-instrucional de divulgar saberes técnicos, caracterizado pela exposição pormenorizada de informações e procedimentos vários e pela preocupação constante em atender as necessidades práticas do leitoragricultor. A conjunção de todos esses elementos distintivos do gênero, apesar de subordinar a linguagem a seu uso concreto e converter o caráter

$\overline{{ }^{1} \text { Cf. Aguilar, 2006, p. } 264 .}$

${ }^{2}$ Cf. de Meo, 2005, p. 25: La lingua agricola [...] è soprattutto quella che emerge dalle opere di carattere specifico, a cominciare dal "De agri cultura" di Catone (II secolo a.C) per giungere all' "Opus agriculturae" di Palladio, in 14 libri, testimonianza dell'interesse per l'argomento ancora vivo nel IV secolo.

${ }^{3}$ Cf. de Meo, 2005, p. 34.

${ }^{4}$ Cf. Martin e Gaillard, 1990, p. 176-177: Le tout dans un style d'un classicisme parfait, constamment soutenu, dont l'emploi s'explique sans doute par son désir de donner à l'agronomie ses lettres de noblesse, en ne se permettant aucun relâchement, aucune négligence au niveau de l'écriture.

${ }^{5}$ Cf. Armendáriz, 1995, p. 32-33.

${ }^{6}$ Cf. Marouzeau, 1946, p. 287-289: La recherche du rythme dans l'énoncé, fait universel, a joué un rôle particulièrement important en latin, à toutes les époques. Outre les raisons qu'a l'écrivain ou le sujet parlant d'ordonner les éléments de l'énoncé en fonction du sens et selon les régles de la syntaxe, il éprouve en outre le besoin dans certains cas de réaliser une succession de membres et d'intervalles propre à satisfaire l'oreille.

${ }^{7}$ Cf. Armendáriz, 1995, p. 32. 
informativo em função dominante do texto, não impede a vontade de estilo que confere ao De re rustica pretensões literárias.

O livro IX, apesar de reservar um primeiro capítulo à construção de viveiros para animais selvagens, refere-se basicamente à apicultura: as várias espécies de abelhas, a escolha do lugar apropriado para o apiário, tipos de abrigo para as colmeias, identificação da abelha rainha, remédios para as abelhas, entre outros temas atinentes a esses insetos. Um aspecto notável desse livro é o emprego de citações de versos das Geórgicas IV de Virgílio como garante único de passagens de caráter técnico, o que indica a existência de uma rede de relações intertextuais que revelam a admiração que o agrônomo nutria pelo vate mantuano. E nessa admiração pode haver a conveniência de se apresentar sob a fiança legitimadora de uma tradição, e assim se autolegitimar. ${ }^{8}$

Geórgicas, por sua vez, considerada a obra-prima de Virgílio, ${ }^{9}$ e simultaneamente sua produção menos prestigiada pelo público leitor, ${ }^{10}$ pertence ao gênero poesia didática, cuja tradição literária caracterizada por certos traços distintivos se inicia com Os trabalhos e os dias de Hesíodo, no século VIII a.C. Durante os séculos em que tal forma foi praticada, características internas, como, por exemplo, a onipresença do caráter de ensinamento, o enfoque de temas técnico-filosóficos e a voz de um magister didático que se dirige a um discipulus colaboraram para a particularização do gênero. ${ }^{11}$ Ao iniciar as Geórgicas, o talento poético de Virgílio já estava

\footnotetext{
${ }^{8}$ Cf. Conte e Barchiesi, 2010, p. 87: O texto que cita quer tornar-se por sua vez citável. ${ }^{9}$ Cf. Grimal, 1985, p. 117: Il est certain que les “Géorgiques”, qui sont l'oeuvre de Virgile la plus parfaite, témoignent d'un long travail. L'équilibre de la composition, qui donne aux quatre chants de longueurs voisines, la pureté de la langue, toujours claire et harmonieuse, la vérité des épisodes, la précision d'une pensée qui parvient à illustrer chaque technique de l'agriculture en l'associant à des images inoubliables, rien de tout cela ne saurait avoir été donné par les dieux.

${ }^{10}$ Cf. Polara, 1983, p. 3: Una lunga tradizione che da Concetto Marchesi risale fino al Leopardi vede nelle "Georgiche" l'opera più perfetta di Virgilio, la sua prova più felice tra una raccolta come le "Bucoliche", in cui ancora si avvertono alcuni limiti di inesperienza, $e$ un epos celebrativo come l' "Eneide", rimasto incompiuto e con evidenti segni della mancata rifinitura [...]. Ma di fronte a questa posizione privilegiata che l'autore stesso e la critica più accorta hanno assegnato al poema della campagna c'è l'evidente minore fortuna di cui esso ha sempre goduto presso il grosso pubblico: già nei graffiti di Pompei è enorme la sproporzione fra le citazioni dalle "Bucoliche" e dall' "Eneide", composizioni di grande successo presso le più svariate categorie sociali, e quelle dalle "Georgiche", praticamente ignorate.

${ }^{11}$ Cf. Toohey, 1996, p. 21 apud Trevizam, 2006, p. 147.
} 
assegurado com a obra precedente, as Bucólicas, dez églogas de temas campestres e pastoris. O seu propósito, porém, ao compor um poema sobre temas agrários não foi somente transmitir uma série de conhecimentos técnicos sobre os trabalhos do campo, como, por exemplo, o tempo propício para realizar o plantio e a colheita ou os procedimentos adequados para castrar as colmeias. Se nos fixássemos apenas nesse aspecto temático, a obra seria classificada como um tratado técnico de agronomia; ${ }^{12}$ mas as Geórgicas representam muito mais do que um simples compêndio de aplicação prática sobre métodos a seguir na agricultura. ${ }^{13}$ Essa afirmação surge de um fato facilmente comprovável: da totalidade de preceitos úteis e práticos em cada ramo da agricultura, Virgílio seleciona apenas os que convêm à finalidade artística e à gravidade moral de cada episódio. Tal atitude é significativa, porque estabelece uma clara distinção entre a poesia didática virgiliana e os tratados técnicos relativos a assuntos rurais. Virgílio desenvolve temas de menor interesse prático para agricultores e omite outros de fundamental importância. Esse silêncio indica que o poeta seleciona os temas de maior potencial estético, privilegiando a função poética em detrimento da informativa. ${ }^{14}$

A seguir, analisamos comparativamente dois trechos selecionados do De re rustica (IX 4-5) e das Geórgicas IV - o primeiro se refere ao prefácio e ao proêmio, respectivamente, das referidas obras; o segundo, à descrição de aspectos físicos e comportamentais dos diferentes tipos de abelhas (rainhas e operárias) - , para compreendermos um pouco melhor o tratamento linguístico-literário decorrente de orientações genéricas distintas que os

${ }^{12}$ Cf. Doody, 2007. p. 182: Traditionally, technical writing has been defined in terms of its utility and in opposition to literature, and this position still has some currency. [...] the rigidity of the distinction between literary and nonliterary text makes it difficult to explore shared material and shared concerns across didactic poetry and prose writings [...]. There has been an alternative movement, however, that argues for more flexible boundaries between technical and other sorts of writing produced at Rome. The idea of a "spazio letterario", introduced by Gugliemo Cavallo and others, has been particularly productive in breaking down rigid divisions between literary and nonliterary texts in antiquity: despite their differences, almost all texts were written and read in the same milieu, governed by the same rules of literary production. ${ }^{13}$ Cf. Sêneca, 2004, p. 400: Sêneca (4 a.C.-65 d.C.), na Epístola LXXXVI, 15, já fazia justiça à opinião de que Virgílio compusera um poema: O nosso poeta, aliás, cuidava menos da verdade que da beleza literária, interessado como estava em proporcionar prazer aos seus leitores, e não em dar lições aos homens do campo! (trad. J. A. Segurado e Campos). ${ }^{14}$ Cf. Trevizam, 2006, p. 157: Quanto à seletividade, já foi observado à exaustão que, ao lado da omissão de certos assuntos de fundamental importância para os "agricolae" romanos, Virgílio dá ênfase aparentemente injustificada a outros desprovidos do mesmo peso prático. 
autores conferem às suas obras e os aspectos relacionados à construção dos significados particulares das obras.

\section{Proêmio das Geórgicas IV uersus Prefácio do livro IX do De Re Rustica}

Como primeiro elemento de cotejo entre as Geórgicas IV e o livro IX do De re rustica, elegemos as unidades textuais de apresentação das respectivas obras, que sinalizam os traços norteadores dos textos postos em confronto.

O proêmio das Geórgicas IV é breve: sete versos distribuídos de forma equilibrada em três períodos de 2, 3 e 2 versos, respectivamente:

Protinus aerii mellis caelestia dona exsequar: hanc etiam, Maecenas, adspice partem.

Admiranda tibi leuium spectacula rerum, magnanimosque duces totiusque ordine gentis mores et studia et populos et proelia dicam. In tenui labor; at tenuis non gloria, si quem numina laeua sinunt auditque uocatus Apollo. ${ }^{15}$

No primeiro período, os termos que iniciam os dois primeiros versos que o compõem — protinus (v. 1), "prosseguindo", e exsequar (v. 2), "relatarei" - indicam a continuidade dos livros precedentes. A expressão aerii mellis caelestia dona (v. 1), "dons celestes do aéreo mel”, anuncia o único tema contemplado no canto, a apicultura (Varrão, por exemplo, uma das fontes ${ }^{16}$ de Virgílio, aborda-a juntamente com a criação de outros

\footnotetext{
${ }^{15}$ Geórg. IV 1-7: "Prosseguindo, os dons celestes do aéreo mel relatarei: essa parte também, Mecenas, considera. Para tua admiração, direi espetáculos de pequenos assuntos e, em ordem, magnânimos chefes, costumes, ocupações, povos e combates de nações inteiras. Pequeno o trabalho; mas não pequena a glória, se os deuses contrários o permitem e Apolo invocado ouve" (trad. nossa).

${ }^{16}$ As fontes consultadas por Virgílio poderiam ser organizadas em duas categorias: fontes técnicas e fontes poéticas. Cf. Gigante, 1982, p. 123-124: Quanto alle fonti, Virgilio ha tenuto presente la "Historia animalium" di Aristotele (libro IX, cap. 40) e soprattutto Varrone, di cui il lungo cap. 16 del III libro "De re rustica", dedicato alle api, offre la possiblità di confronti con numerosi passi appartenenti alla prima parte del IV libro delle "Georgiche". [...] Tra le fonti poetiche ricordiamo soprattutto Lucrezio, il grande maestro di Virgilio, che da lui prende espressioni e immagini, trasferendole in contesti diversi,
} 
animais da casa de campo), e contrapõe uma ideia de pureza e suavidade à imagem lúgubre que encerra o canto anterior (III), que termina com o funesto episódio da peste que assola os animais na região dos Alpes. A forma aerii retoma uma concepção dos Antigos, segundo a qual o mel caía do céu e se depositava sobre as flores; ${ }^{17}$ e caelestia dona sugere que ele é um dom do céu e dos deuses. O poeta se dirige a Maecenas ${ }^{18}$ (na mesma posição que essa palavra ocupa no livro I, v. 2), a quem dedica o poema, e o convoca em tom solene para que adspicat ${ }^{19}$ (v. 2), "considere", o seu canto. No segundo período (v. 3-5), o poeta estabelece a semelhança entre as abelhas e a sociedade humana: as formas admiranda tibi... spectacula ${ }^{20}$ (v. 3), "espetáculos... para tua admiração", antecipam o caráter surpreendente e maravilhoso das imagens que serão apresentadas aos leitores; enquanto os termos de estrato militar, social e político que caracterizam o livro IV “magnanimos... duces totius... gentis/ mores et studia et populos et proelia (v. 4-5), "magnânimos chefes, costumes, ocupações, povos e combates de nações inteiras" - conferem-lhe um tom épico que contrasta com a expressão leuium... rerum (v. 3), "pequenos assuntos", a qual confirma a vinculação estética de Virgílio à poética alexandrina, ao ideal calimaquiano de leveza e brevidade. ${ }^{21}$ A estrutura mesma desse proêmio é exemplo modelar de elaborada concisão. ${ }^{22}$ No segmento final (v. 6-7), que traz a expressão in tenui $\operatorname{labor}^{23}$ (v. 6), "pequeno o trabalho", o poeta reafirma o ideal alexandrino da

arricchendole cosí di sfumature e significati nuovi; ma, rispetto a Lucrezio, che espone una dottrina filosofica di altri, Virgilio canta la natura e gli animali con grande partecipazione, $e$ cura $i$ particolari, anche minimi, con amore e sensibilità acutissima.

${ }^{17}$ Cf. Aristóteles, 2006, p. 238: V, 22, 4. [...] o mel é uma substância que cai do ar, sobretudo por altura do nascimento dos astros e quando se forma o arco-íris. Em geral não há mel antes do nascer das Plêiades [maio]. E, ainda, [...] o mel não é ela [abelha] que o faz, mas recolhe-o quando ele se deposita.

${ }^{18}$ Cf. Virgílio, 2007, p. 137-138: La posizione del nome assicura che le "Georgiche" sono formalmente dedicate a Gaio Mecenate [I, 2; II, 41; III, 41; IV, 2], influente cavaliere di origine etrusca, ispiratore della politica culturale di Augusto e protettore di Virgilio (nota de Alessandro Barchiesi ao livro I das Geórgicas).

${ }^{19}$ Cf. Gigante, 1982, p. 126: [...] "aspice" contiene una sfumatura di tono quasi religioso, e prelude a qualquosa di importante, di impegnativo.

${ }^{20}$ Cf. Gigante, 1982, p. 126: "admiranda... spetacula": sono visioni continue che il poeta nel corso del livro offre al lettore e che danno, di volta in volta, il senso della sorpresa, del miracolo.

${ }^{21}$ Cf. Gigante, 1982, p. 126-127.

${ }^{22}$ Cf. Virgílio, 2007, p. 175 (nota de Alessandro Barchiesi ao livro IV das Geórgicas).

${ }^{23}$ Cf. Gigante, 1982, p. 127: [...] nell'espressione “in tenui labor" (v. 6), nella quale è 
brevidade, no início do mesmo verso em que destaca o valor de sua obra tenuis non gloria (v. 6), "não pequena a glória" —, sugerindo sua vinculação a essa escola. Por fim, invoca-se Apolo, deus protetor da poesia. ${ }^{24}$ De fato, a ênfase do proêmio recai no contraste entre a pequenez das abelhas e a grandiosidade de seu modo de viver, que se apresenta como motivo central do livro IV. A disposição mesma dos dois livros finais das Geórgicas sugere esse contraste, seja pelo movimento do grande ao pequeno (dos animais maiores às abelhas), seja pelo aprofundamento da complexidade da relação homem-natureza. ${ }^{25}$ Passemos, agora, ao prefácio do livro IX do De re rustica:

Venio nunc ad tutelam pecudum siluestrium et apium educationem: quas et ipsas, Publi Siluine, uillaticas pastiones iure dixerim; siquidem mos antiquus lepusculis capreisque, ac subus feris iuxta uillam plerumque subiecta dominicis habitationibus ponebat uiuaria, ut et conspectu suo clausa uenatio possidentis oblectaret oculos, et cum exegisset usus epularum, uelut e cella promeretur. Apibus quoque dabatur sedes adhuc nostra memoria uel in ipsis uillae parietibus excisis, uel in protectis porticibus ac pomariis. Quare quoniam tituli, quem praescripsimus huic disputationi, ratio reddita est, ea nunc quae proposuimus singula persequamur. ${ }^{26}$

O prefácio inicia-se com a expressão Venio nunc, "Passo, agora", que (tal qual o protinus... exsequar das Geórgicas IV) indica a continuidade dos livros precedentes. $\mathrm{O}$ fragmento tutelam pecudum siluestrium et apium

racchiuso l'ideale alessandrino (soprattutto callimacheo) del $\lambda \varepsilon \pi \tau o ́ \varsigma$, che ritroviamo anche in altri poeti dell'età augustea.

${ }^{24}$ Cf. Polara, 1983, p. 17-18: Il poema didascalico doveva contenere nel suo proemio tre elementi: una "propositio", che informava il lettore sul contenuto dell'opera, una "dedicatio", con cui il poeta onorava il personaggio per cui l'opera era scritta, ed una "inuocatio" che chiamava le divinità in aiuto alla difficile impresa.

${ }^{25}$ Cf. Virgílio, 2007, p. 175 (nota de Alessandro Barchiesi ao livro IV das Geórgicas).

${ }^{26}$ RR. IX Praefatio: "Passo, agora, ao trato dos animais selvagens e ao cuidado das abelhas: essas mesmas coisas, Públio Silvino, eu também chamaria com justiça de uillatica pastio; pois o costume antigo estabelecia reservas para as lebres, para os cabritos e para os porcos selvagens junto da casa de campo, quase sempre abaixo das habitações senhoriais, para que a visão das caçadas em recinto fechado deleitasse os olhos do senhor e, tendo-o exigido o costume dos banquetes, dali se retirasse como de uma despensa. Dava-se morada às abelhas, ainda em nossa época, quer nas próprias paredes escavadas da casa de campo, quer nos pórticos cobertos e nos pomares. Então, visto que a razão do título que preestabelecemos para essa discussão foi referida, desenvolvamos agora, um a um, os tópicos propostos" (trad. nossa). 
educationem, "cuidado dos animais selvagens e à criação das abelhas", anuncia que a apicultura é abordada juntamente com a criação de outros animais da casa de campo (como o fizera Varrão), o que a coloca no mesmo plano das demais criações da casa de campo. A leitura do livro, porém, revela que a criação de outros animais ocupa apenas o primeiro capítulo, enquanto a apicultura se estende pelos quinze capítulos restantes, em que aspectos variados do tema são abordados, confirmando que a apicultura ocupa um lugar de destaque entre as demais criações por sua importância econômica na sociedade romana. Em seguida, o agrônomo assume a vOz de magister didático e se dirige a Publio Siluino, o amigo a quem dedica o texto e personificação do leitor. Segue-se a retomada e desenvolvimento dos temas já anunciados de forma concisa no início do prefácio, em que se percebe a postura político-econômica 'moderna' ${ }^{27}$ do agrônomo que se mobiliza para reformar as práticas agrícolas tradicionais. Ao referir-se à criação de animais da casa de campo, ele menciona um mos antiquus, ${ }^{28}$ "o costume antigo", que estabelecia reservas para os animais, indicando um tipo obsoleto de criação de animais selvagens para uso doméstico que se opõe à maneira 'moderna' que ele defende, cujo fim é, sobretudo, gerar lucro para o proprietário; e enumera os animais criados pelos antigos, lepusculis capreisque, ac subus feris, "para as lebres, para os cabritos e para os porcos selvagens", em que se prenuncia uma crítica ao 'costume antigo', pois as lebres não são próprias para criação em cativeiro, visto que pela pequenez de seus corpos elas se intrometem pelas aberturas dos cercados

\footnotetext{
${ }^{27}$ Cf. Martin, 1971, p. 319: Columelle estime donc que les techniques agricoles sont loin d'avoir été développées comme elles l'auraient pu et qu'elles sont restées, sinon primitives, du moins empiriques.

${ }^{28}$ Cf. Pereira, 2009, p. 357: Os Romanos tinham como suporte fundamental e modelo do seu viver comum a tradição, no sentido de observância dos costumes dos antepassados, "mos maiorum”. Esta ideia é, pelo menos, tão antiga como Énio, em fragmento muitas vezes citado: 'Nos costumes e varões antigos se apoia o Estado Romano'. Não confundir a referência ao mos antiquus a uma possível crítica do agrônomo ao mos maiorum; pelo contrário, Columela é um defensor dos costumes tradicionais e das ideias morais romanas labor, fides, honor, entre outras —, como Virgílio, ele era um escritor engajado, e, ao criticar um determinado 'costume antigo', cuja origem é difícil determinar, ele se refere às práticas que conduziram Roma à crise agrícola de seu tempo, obrigando o Estado a importar alimentos como nos tempos das guerras civis. René Martin (1971, p. 311) assim se expressa sobre o assunto: Face à la crise agricole de son temps, Columelle ne se borne pas à diagnostiquer le mal et à déterminer ses causes; il propose aussi un certain nombre de remèdes, qu'il nous faut étudier maintenant, et qui le font passer, ainsi que nous le verrons, de l'économie et de la philosophie à la politique.
} 
e fogem, após o pater familias ter gasto tempo e recursos para alimentá-las. Ao referir-se à apicultura, o agrônomo alude à permanência de práticas agrícolas ultrapassadas (mos antiquus), que adhuc nostra memoria, "ainda em nossa época”, estabelecia as colmeias quer in ipsis uillae parietibus excisis, uel in protectis porticibus ac pomariis, "nas próprias paredes escavadas da casa de campo, quer nos pórticos cobertos e nos pomares". Aqui, também, estabelece-se o contraste entre um tipo de manejo já superado em seu tempo e uma prática 'moderna', que gera maior produtividade das colmeias e, consequentemente, maior lucro para o proprietário. No fim do prefácio vem a indicação da ordem linear adotada na exposição da matéria — ea nunc quae proposuimus singula persequamur, "desenvolvamos agora, um a um, os tópicos propostos".

Nota-se que o prefácio do livro IX de Columela se configura como uma espécie de resumo de suas concepções político-culturais e econômicas: após indicar os temas do livro (criação de animais e apicultura), ele menciona em linhas gerais o mos antiquus que pretende reformar, contribuindo assim para a grandeza de Roma; e na exposição da matéria, encontramos expressões disseminadas que revelam críticas ao "costume antigo". Nesse aspecto, o prefácio se identifica, ainda que lateralmente, com o proêmio das Geórgicas $I V$, que, ao destacar o contraste entre a pequenez das abelhas e a grandiosidade de seu modo de viver, representa a colmeia como exemplo modelar de organização político-econômico-social para a sociedade humana.

\section{Eleição de um rei e características das melhores abelhas}

O segundo elemento particularizado do cotejo entre as obras em estudo se refere à descrição de aspectos físicos e comportamentais dos diferentes tipos de abelhas (rainhas e operárias), e à eleição das melhores quanto à capacidade melífera. Tal classificação é essencial ao manejo das abelhas e à organização do sistema produtivo nos fundi, uma vez que as diferentes espécies apresentam variada habilidade para produzir mel. ${ }^{29}$ Antes de passarmos à análise dos trechos selecionados, convém fazer uma ressalva: os antigos tomavam as rainhas por reis e, ao descrevê-los se referiam na verdade a rainhas. A descoberta de que os enxames eram guiados por fêmeas ocorre apenas no século XVII. ${ }^{30}$

\footnotetext{
${ }^{29}$ Cf. Trevizam, 2006, p. 325.

${ }^{30}$ Cf. Barchiesi, 2007, p. 175: La scoperta che gli sciami sono in realtà guidati da una "regina" è giunta solo nel XVII secolo.
} 
Virgílio descreve primeiro dois tipos de reis (v. 88-94); e, na seção que vem imediatamente, duas espécies de abelhas comuns (v. 95-102) que o poeta vincula, uma a uma, a determinado rei. O modo especial de organização do tema e, sobretudo, as escolhas vocabulares, têm sugerido a alguns críticos a leitura desses episódios como alegoria da realidade histórica do poeta. Virgílio redigiu esse canto, provavelmente, em 30 a.C., um ano após a batalha de Ácio que selou a vitória de Augusto sobre Marco Antônio. Naturalmente, os acontecimentos desse período ofereceram ao poeta elementos para o desenvolvimento de intenções político-ideológicas evidentes a seus contemporâneos, que ele soube integrar à estrutura do poema. ${ }^{31}$ Alguns críticos formularam a hipótese de que, na campanha político-militar que então se desenvolveu, Augusto teria sido identificado a Apolo, deus da poesia, ordem e harmonia e, ainda, da medicina, cujo culto se realiza durante o dia; Marco Antônio, por outro lado, a Dioniso (de origem oriental), deus do vinho e, por extensão, do irracional e insensato, cujas cerimônias se realizavam durante a noite. ${ }^{32}$ De acordo com essa leitura, tais relações foram aproveitadas para estabelecer uma oposição ideológica essencial à estrutura das Geórgicas: Augusto-Roma-Ocidente e Marco Antônio-Egito-Oriente. Vejamos a seção referente aos "reis" (IV 88-94):

Verum, ubi ductores acie renocaueris ambo, deterior qui uisus, eum, ne prodigus obsit, dede neci; melior uacua sine regnet in aula. Alter erit maculis auro squalentibus ardens (nam duo sunt genera): hic melior insignis et ore et rutilis clarus squamis; ille horridus alter

\footnotetext{
${ }^{31}$ Cf. Polara, 1983, p. 7-8: [...] sotto l'immagine dell'agricoltura, e accompagnata dalle lodi che all'agricoltura sono riservate, è presentata sempre la "Saturnia tellus", l'Italia, in una contrapposizione ideale fra i costumi laboriosi e frugali degli italici - e quindi di Ottaviano - e quelli molli e rilassati degli orientali — e quindi di Antonio —; cosí l'esaltazione dell'agricoltura come lavoro, e lavoro manuale, serve a mettere in secondo piano, come nonlavoro e quindi non-valore, l'attività speculativo-filosofica e teorico-politica di alcuni settori dell'aristocrazia senatoria che ancora potevano nutrire qualche inconfessata simpatia per le posizioni dei cesaricidi, pur sconfitte militarmente e politicamente; cosí soprattutto la necessità della pace interna e della fine delle guerre civili, condizione indispensabile per una proficua attività agricola, porta nella parte finale del primo libro delle Georgiche alla proposta di una totale delega della gestione dello stato al princeps in cambio della restituzione di condizioni che garantiscano la sicurezza del lavoro.

${ }^{32}$ Cf. Bauzá, 2008, p. 61.
} 
desidia latamque trahens inglorius aluom. ${ }^{33}$

Logo após a famosa cena da batalha das abelhas (v. 67-87) — alegoria da batalha de Ácio, em que Otaviano, vencedor, é contraposto a Marco Antônio, perdedor inglório - , vem a primeira seção eleita para análise, em que se apresentam dois tipos de reis (v. 88-94). Esse fragmento também pode ser interpretado simbolicamente, pois a terminologia virgiliana é rica em possibilidades significativas que sugerem tal interpretação. No primeiro verso dessa passagem, por exemplo, a forma ductores (v. 88), "líderes", evoca uma imagem militar e monárquica que identifica os reis das abelhas aos dos homens. O melior (v. 90), "melhor", é aquele ardens (v. 91), "que brilha", e clarus (v. 93), "brilhante", e que regnet in aula (v. 90), "reina na corte"; o pior, ao contrário, é aquele que arrasta latamque...aluom (v. 94), "enorme ventre", inglorius (v. 94), "sem glória". Esses termos, que remetem ao gênero épico, aguçam a imaginação do leitor e sugerem relações entre o mundo das abelhas e a realidade histórica à época em que o poeta escreve, mas não há consenso a respeito de tais relações. ${ }^{34}$ Vejamos agora a seção subsequente (IV 95-102):

Vt binae regum facies, ita corpora plebis: namque aliae turpes horrent, ceu puluere ab alto quom uenit et sicco terram spuit ore uiator aridus; elucent aliae et fulgore coruscant ardentes auro et paribus lita corpora guttis. Haec potior suboles: hinc caeli tempore certo dulcia mella premes, nec tantum dulcia quantum et liquida et durum Bacchi domitura saporem. ${ }^{35}$

\footnotetext{
${ }^{33}$ Geórg. IV 88-94: "Mas, quando tiveres chamado do combate os dois líderes, entrega à morte aquele que pareceu pior, para que consumindo não seja prejudicial; deixa que reine o melhor na desimpedida corte. Um (pois duas são as espécies) será brilhante com pintas incrustadas de ouro. Esse, insigne por seu aspecto e distinto por suas rutilantes escamas, é o melhor; aquele outro é repugnante por sua indolência, arrastando inglório enorme ventre" (trad. nossa).

${ }^{34}$ Cf. Thomas, 2003, p. 162, in Virgil, 2003: The lines on the good and bad king have been seen as pure allegory, representing Octavian and Antony, but Virgil's treatment of the bees, while symbolic, does not suit such strict equation.

${ }^{35}$ Geórg. IV 95-102: "Dois são os aspectos dos reis, assim como os corpos da plebe: porque umas são disformes e hirsutas, como o viajante sedento quando vem por um leito de pó e cospe terra de sua garganta seca; outras reluzem e cintilam de esplendor, brilhantes do ouro e por seus corpos mosqueados de simétricas manchas. Essa é a melhor estirpe: dela extrairás na estação certa do ano doces
} 
O poeta descreve, também comparativamente, dois tipos de abelhas operárias, identificando-as ao seu respectivo rei: ${ }^{36}$ Vt binae regum facies, ita corpora plebis (v. 95), "Do mesmo modo que são dois os aspectos dos reis, assim os corpos da plebe"; e nesse verso está assinalada a imagem humanizada das abelhas como súditos de reis ${ }^{37}$ (os romanos contemporâneos de Virgílio não se viam como súditos de rei, mas cidadãos de uma República...). Os termos empregados situam as duas espécies em campos opostos: as abelhas de tipo inferior, turpes horrent (v. 96), "são disformes e hirsutas", e suas características físicas são indicadas por meio de um símile - puluere ab alto quom uenit et sicco terram spuit ore uiator aridus (v. 96-98), "como a terra que o viajante sedento cospe de sua garganta seca, quando vem por um leito de pó" - ; por sua vez, as de tipo superior apresentam atributos positivos que as vinculam à figura do rei vencedor: elucent... et fulgore coruscant (v. 98), "resplandecem e vibram radiantes". Essas relações são intensificadas pelos três versos finais (v. 100-102), que afirmam a superioridade da primeira espécie, apta a produzir dulcia mella (v. 101), "doces méis", que durum Bacchi domitura saporem, (v. 102), "hão de amenizar o sabor áspero de Baco". Notase que o termo durum, "associado a elementos variados da vida rural das Geórgicas e que se reveste de grande importância para sua compreensão", ${ }^{38}$ evoca aqui não a ideia de grandes esforços a serem realizados pelo agricola para subjugar a natureza.

Virgílio subordina a organização do conteúdo instrucional à economia do texto poético, articulando dados técnicos que, ao menos em um caso, resultam em informação imprecisa, mas verossímil. De fato, o poeta restringe a descrição das várias espécies de abelhas então conhecidas a apenas dois tipos, o que lhe permitiu estabelecer oposições sugestivas e funcionais à organização do tema; mas Varrão, uma das fontes de Virgílio,

méis; não só doces, mas também cristalinos, e que hão de corrigir o sabor áspero de Baco" (trad. nossa).

${ }^{36}$ Cf. Thomas, 2003, p. 164, in Virgil, 2003: Virgil concerned as ever with a precise human approximation, has two varieties of bee under each of the two kings, neatly related in appearance to their leaders.

${ }^{37}$ Cf. Grimal, 1985, p. 123: [...] avec les abeilles, nous sommes déjà presque parmi les hommes. Les autres animaux ne savent pas s'organizer en sociétés. Les abeilles au contraire donnent un exemple de discipline et de concorde, qui peut servir de modèle (et de leçon) aux contemporains du poète. Elles pratiquent toutes les vertus que devraient pratiquer les humains, l'ardeur au travail, l'heroïsme, pour défendre leur roi et [...] elles connaissent la valeur de la gloire!

${ }^{38}$ Cf. Trevizam, 2006, p. 327. 
enumera oito tipos de abelhas, indicando "a possibilidade de divisão dos tipos em duas categorias [...] e de que, em pelo menos um deles, as abelhas fossem variegadas" e, contrariando Virgílio, "a variedade apresentada como inferior em Varrão não se caracteriza por ser 'eriçada' (horridus — v. 93) ou de ventre volumoso (latamque... aluum — v. 94), mas sim pela pele escura e pela propensão a fomentar 'revoluções' e a evadir-se". 39

Columela, por outro lado, segue caminho inverso ao de Virgílio para descrever as abelhas: primeiro trata das operárias (IX 3); e muito adiante (IX 10), dos reis. Observa-se que esse distanciamento, por si mesmo, restringe uma eventual leitura alegórica das passagens, caso admitíssemos reminiscências político-ideológicas virgilianas nessas passagens. Além disso, os termos empregados na exposição do tema pertencem ao campo da linguagem técnica agrária, o que torna tal leitura ainda mais improvável. Vejamos a primeira seção:

Peripateticae sectae conditor Aristoteles in iis libris, quos de animalibus conscripsit, apium examinum genera conplura demonstrat, earumque alias uastas sed glomerosas easdemque nigras et hirsutas apes habent: alias minores quidem, sed aeque rotundas et fusci coloris horridique pili: alias magis exiguas, nec tam rotundas, sed obesas tamen et latas, coloris meliusculi: nonnullas minimas gracilesque, et acuti alui, ex aureolo uarias atque leues: eiusque auctoritatem sequens Vergilius, maxime probat paruulas, oblongas, leues, nitidas,

Ardentes auro, et paribus lita corpora guttis, ${ }^{40}$

moribus etiam placidis. Nam quanto grandior apis, atque etiam rotundior, tanto peior. Si uero saeuior, maxime pessima est. ${ }^{41}$

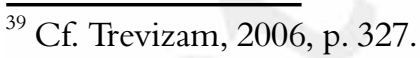

${ }^{40}$ Geórg. IV 99.

${ }^{41} R R$. IX 3: "Aristóteles, fundador da escola peripatética, apresenta vários tipos de enxames de abelhas nos livros que escreveu sobre os animais: alguns deles têm abelhas grandes, mas globulares, elas mesmas negras e hirsutas; outras, decerto, menores, mas igualmente redondas, de cor negra e de pelos eriçados; outras, menores, nem tão redondas, mas pesadas, largas e de cor um pouco mais bela; algumas são muito pequenas e delgadas, de ventre afilado, pintadas de ouro e lisas. Virgílio, que segue a autoridade dele, sobretudo aprova as abelhas pequenas, oblongas, lisas e brilhantes, 'Brilhantes do ouro e por seus corpos mosqueados de simétricas manchas' e, ainda, de costumes pacíficos. Pois, quanto maior e também mais redonda a abelha, tanto pior. Se, porém, um tanto feroz, essa, sobretudo, é a de pior qualidade" (trad. nossa). 
No capítulo 3, o agrônomo descreve quatro tipos de abelhas operárias, com base na autoridade de Aristóteles: ${ }^{42}$ (a) uastas sed glomerosas easdemque nigras et hirsutas apes, "abelhas grandes, mas globulares, elas mesmas negras e hirsutas"; (b) minores... sed aeque rotundas et fusci coloris horridique pili, "menores, mas igualmente redondas, de cor negra e de pelos eriçados"; (c) magis exiguas, nec tam rotundas, sed obesas tamen et latas, coloris meliusculi, "menores, nem tão redondas, entretanto, pesadas, largas e de cor um pouco mais bela"; (d) minimas gracilesque, et acuti alui, ex aureolo uarias atque leues, "muito pequenas e delgadas, de ventre afilado, pintadas de ouro e lisas"; eiusque auctoritatem sequens Vergilius, maxime probat paruulas, oblongas, leues, nitidas, "Virgílio, que segue a autoridade dele [Aristóteles], sobretudo aprova as abelhas pequenas, oblongas, lisas e brilhantes". Notase que o agrônomo classifica os tipos de abelhas segundo critérios físicos (forma, tamanho, cor e pelos), partindo das mais redondas, maiores, escuras e peludas até chegar às delgadas, menores, brilhantes e lisas. Considerados inferiores, os três primeiros tipos têm algumas características físicas semelhantes, mas diferem entre si por um ou outro aspecto físico que permite ao apicultor distinguir um tipo de outro. Essas semelhanças entre os tipos inferiores de abelhas operárias podem estar na origem da redução efetuada por Virgílio, a partir de Aristóteles, a apenas dois — um inferior, que abarcaria os três primeiros tipos, e outro superior, o quarto tipo - , fazendo-os coincidir com os dois tipos de reis. O quarto tipo é inconfundível - minimas gracilesque, et acuti alui, ex aureolo uarias atque leues, "muito pequenas e delgadas, de ventre afilado, pintadas de ouro e lisas" - e representa a espécie melífera recomendada pelo agrônomo aos apicultores, com aval de Virgílio, pois ela se destaca por sua mansidão e capacidade de produzir mel. A descrição dos dois tipos de reis vem apenas no capítulo 10:

Sunt autem hi reges maiores paulo et oblongi magis quam ceterae apes, rectioribus cruribus, sed minus amplis pinnis, pulchri coloris et nitidi, leuesque ac sine pilo, sine spiculo, nisi quis forte pleniorem quasi capillum, quem in uentre gerunt, aculeum putat, quo et ipso tamen ad nocendum non utuntur. Quidam etiam infusci atque hirsuti reperiuntur, quorum pro habitu damnabis ingenium.

\footnotetext{
${ }^{42}$ Cf. Aristóteles, 2006, p. 237: V, 22, 1. As variedades das abelhas são: uma pequena, arredondada e matizada, que é a melhor; há outra mais comprida, parecida com o abelhão; e uma terceira, chamada ladra (que é negra e com o abdômen chato); em quarto lugar vem o zangão, que, em dimensões, é a maior de todas, que não tem ferrão e é preguiçoso.
} 
Nam duo sunt regum facies, ita corpora plebis.

Alter erit maculis auro squalentibus ardens

Et rutilis clarus squamis. ${ }^{43}$

Atque hinc maxime probatur, qui est melior: nam deterior, sordido sputo similis, tam foedus est,

quam puluere ab alto

Cum uenit et sicco terram spuit ore uiator. ${ }^{44}$

Et, ut idem ait,

Desidia latamque trahens inglorius aluum. ${ }^{45}$

Omnes igitur duces notae deterioris

Dede neci, melior uacua sine regnet in aula. ${ }^{46}$

Qui tamen et ipse spoliandus est alis, ubi saepius cum examine suo conatur eruptione facta profugere. Nam uelut quadam compede retinebimus erronem ducem detractis alis, qui fugae destitutus praesidio finem regni non audet excedere, propter quod ne ditionis quidem suae populo permittit longius enagari.

${ }^{43}$ Geórg. IV 92, 91 e 93 (nessa ordem).

${ }^{44}$ Geórg. IV 96-97. A forma ceu que antecede puluere foi substituída por quam.

${ }^{45}$ Geórg. IV 94.

${ }^{46}$ Geórg. IV 90.

${ }^{47} R R$. IX 10: "Esses reis, porém, são um pouco maiores e mais alongados que as demais abelhas, com pernas mais retas, mas de asas menos amplas, de cor bela e brilhante, lisos, sem pelo e sem ferrão, a não ser que acaso alguém julgue ferrão algo semelhante a um pelo mais grosso que produzem no ventre, e de que, entretanto, em si não se servem para fazer dano. Encontram-se, ainda, alguns fuscos e hirsutos, cuja natureza desaprovarás pelo aspecto. 'Dois são os aspectos dos reis, assim como os corpos da plebe: um será brilhante com pintas incrustadas de ouro, insigne por seu aspecto e distinto por suas rutilantes escamas'. E, sobretudo, aprova-se aquele que é melhor; pois o inferior, semelhante a um escarro imundo, é tão asqueroso 'como o viajante sedento quando vem por um leito de pó e cospe terra de sua garganta seca'. E, como diz o mesmo poeta, 'repugnante por sua indolência, arrastando inglório enorme ventre'. Todos os chefes, portanto, da espécie pior, 'entrega à morte, deixa que reine o melhor na desimpedida corte'. Ele próprio, contudo, deve também ser espoliado das asas, quando tenta muitas vezes fugir em debandada com seu enxame; pois, subtraídas suas asas, reteremos o chefe errante como que com grilhões e, destituído do recurso de fuga, não ousa 
O agrônomo descreve dois tipos comuns de reis encontrados em enxames domésticos, omitindo os demais tipos que poderiam ser encontrados em enxames silvestres: (a) maiores paulo et oblongi magis quam ceterae apes, rectioribus cruribus, sed minus amplis pinnis, pulchri coloris et nitidi, leuesque ac sine pilo, sine spiculo, "um pouco maiores e mais alongados que as demais abelhas, com pernas mais retas, mas de asas menos amplas, de cor bela e brilhante, lisos, sem pelo e sem ferrão" e (b) Quidam... infusci atque hirsuti... quorum pro habitu damnabis ingenium, "alguns fuscos $\mathrm{e}$ hirsutos, cuja natureza desaprovarás pelo aspecto”. A descrição tem caráter prescritivo: o tipo inferior, escuro e hirsuto, deve ser eliminado; o outro, superior, brilhante e sem pelo, deve ser preservado. Esse recorte atende às demandas específicas de apicultores, que devem capturar e criar apenas enxames cuja habilidade de produzir mel em quantidade e qualidade lhes assegure lucros. De modo geral, essa descrição coincide com a de Virgílio, mas difere quanto às motivações: o poeta mantuano, sem se descuidar da transmissão de preceitos instrucionais, restringe a descrição das várias espécies de abelhas então conhecidas a apenas dois tipos, para estabelecer um contraste poeticamente produtivo entre um tipo superior e outro inferior, o que sugeriu a alguns críticos (como já dissemos) que o poeta incorporara concepções político-ideológicas ao texto. O agrônomo, porém, orienta-se por questões práticas e econômicas, organizando sua descrição de acordo com as informações mais seguras e precisas à época, que poderiam auxiliar os apicultores a obter maiores lucros em sua atividade. Para Columela, o agricultor ideal deve ser instruído na "ciência agronômica", conjunto extenso de conhecimentos sobre a produção rural, sob orientação de professores competentes, e apresentar vontade e capacidade de investir a fim de obter maiores lucros. Tal concepção o torna partidário de uma agricultura profissional, em grandes propriedades, rentável apenas com investimentos elevados e em alto nível técnico; daí a necessidade de o agricultor possuir o melhor material, escravos bem nutridos e capazes. ${ }^{48}$

\section{Conclusão}

Finalizada a análise comparativa de trechos selecionados das obras em questão, podemos eleger uma única particularidade distintiva para resumir

exceder o limite do reino, porque não permite ao povo sob seu poder espalhar-se mais além" (trad. nossa).

${ }^{48}$ Cf. Martin, 1971, p. 311-316. 
as diferenças que caracterizam as obras em cotejo. Se considerássemos as três finalidades da retórica antiga - docere, delectare e mouere - poderíamos dizer que, nas Geórgicas, o delectare predomina sobre as demais funções; e no De re rustica, o docere prevalece sobre as demais. Tal diferença vincula-se a condicionamentos genérico-formais que determinam maneiras distintas e especiais de acionar a língua latina e dar forma ao tema, apesar de o assunto desenvolvido nas duas obras confrontadas ser o mesmo, a apicultura.

\section{Referências}

AGUILAR, D. P. El panorama literario técnico-científico em Roma (siglos I-II D.C.) "et docere et delectare". Salamanca: Universidad de Salamanca, 2006.

ARISTÓTELES. História dos animais: I. Trad. Maria de Fátima Sousa e Silva. Lisboa: INCM, 2006.

ARMENDÁRIZ, J. I. G. Agronomía y tradición clásica: Columela en España. Sevilla: Universidad de Cádiz/ Universidad de Sevilla, 1995.

BARCHIESI, A Testo, trad. e note. In: VIRGILIO. Georgiche. Milano: Oscar Mondadori, 2007.

BAUZÁ, H. F. Virgilio y su tiempo. Madrid: Akal, 2008.

COLUMELLA, L. J. M. On agriculture. London: Harvard University Press, 1968 (vol. 2).

CONTE, G. B.; BARCHIESI, A. Imitação e arte alusiva: modos e funções da intertextualidade. In: CAVALLO, G.; FEDELI, P.; GIARDINA, A. O espaço literário da Roma antiga. Vol. I: a produção do texto. Trad. Daniel P. Carrara e Fernanda M. Moura. Belo Horizonte: Tessitura, 2010, p. 87-121.

DOODY, A. Virgil the farmer? Critiques of the "Georgics" in Columella and Pliny. Clasical Philology, Chicago, vol. 102, n. 2, p. 180-197, 2007.

GIGANTE, M. (org.). Lecturae Vergilianae. Napoli: Giannini, 1982.

GRIMAL, P. Virgile, ou la seconde naissance de Rome. Paris: Flammarion, 1985.

MAROUZEAU, J. Traité de stylistique latine. Paris: Les Belles Lettres, 1946.

MARTIN, R. Recherches sur les agronomes latins et leurs conceptions économiques et sociales. Paris: Les Belles Lettres, 1971.

MARTIN, R.; GAILLARD, J. Les genres littéraires à Rome. Paris: Nathan/Scodel, 1990.

MEO, C. de. Lingue tecniche del latino. $2^{\mathrm{a}}$ ed. Bologna: Pàtron, 2005.

PEREIRA, M. H. R. Estudos de história da cultura clássica. Vol. II: cultura romana. Lisboa: Gulbenkian, 2009.

POLARA, G. Le Georgiche di Virgilio: tecnica compositiva ed elaborazione poetica. In: NAZZARO, A. V. (org.). Omaggio Sannita a Virgilio. S. Giorgio del Sannio: Ed. Comune, 1983. 
SÊNECA, L. A. Cartas a Lucílio. Trad. J. A. Segurado e Campos. Lisboa: Calouste Gulbenkian, 2004.

TOOHEY, P. Epic lessons: an introduction to ancient didactic poetry. London/ New York: Routledge, 1996.

TREVIZAM, M. Linguagem e interpretação na literatura agrária latina. Tese de doutorado em Linguística. Campinas: Instituto de Estudos da Linguagem da Unicamp, 2006.

VIRGÍliO. Geórgicas; Eneida. Trad. António Feliciano de Castilho e Manuel Odorico Mendes. Rio de Janeiro: W. M. Jackson, 1949

VIRGIL. Georgics: vol. 1, books I-II. Edited by R. F. Thomas. Cambridge: Cambridge University Press, 2003.

VIRGIL. Georgics: vol. 2, books III-IV. Edited by R. F. Thomas. Cambridge: Cambridge University Press, 2010.

VIRGÍLIO. Bucólicas, Geórgicas, Apéndice Virgiliano. Introducción general J. L. Vidal. Trad., introduciones y notas por Tomás de la Ascención Recio Garcia y Arturo Soler Ruiz. Madrid: Gredos, 2008.

VIRGÍLIO. Bucólicas. Trad. e notas de Odorico Mendes, edição anotada e comentada pelo grupo de trabalho Odorico Mendes. Cotia/ Campinas: Ateliê Editorial/ Editora da Unicamp, 2008.

VIRGÍLIO. Georgiche. Introduzione di Gian Biagio Conte, testo, trad. e note a cura di Alessandro Barchiesi. Milano: Oscar Mondadori, 2007.

VIRGÍLIO. Géorgiques. Texte trad. par E. de Saint-Denis, introduction, notes et postface de J. Pigeaud. Paris: Les Belles Lettres, 1998. 